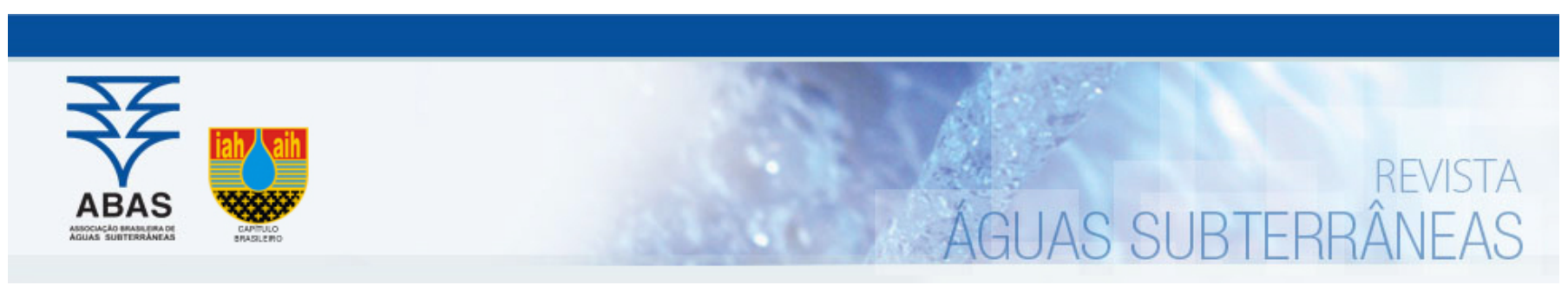

Estudos de Caso e Notas Técnicas

\title{
Avaliação da efetividade das políticas públicas voltadas para a proteção das áreas de captação de água: estudo de caso no município de São Carlos-SP
}

\section{Evaluation of the effectiveness of public policies returned for the protection of areas of water captation: case study in the municipality of São Carlos-SP}

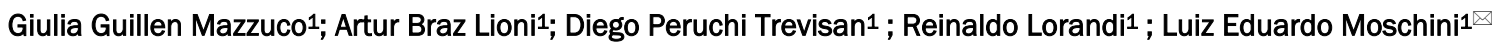 \\ 1 Universidade Federal de São Carlos (UFSCar), São Carlos, SP. \\ $\bowtie$ guillen.giulia@gmail.com, artur.b.lioni@gmail.com, diego.peruchi@gmail.com, lorandir@gmail.com, lemoschini@gmail.com
}

\section{Resumo}

Palavras-chave:

Recursos Hídricos.

Planejamento urbano.

Águas superficiais.

Águas subterrâneas.

Keywords

Water resources.

Urban planning.

Surface water.

Groundwater.

Revisado por pares

Recebido em: 30/11/2017.

Aprovado em: 06/03/2018.

\begin{abstract}
Os estudos referentes avaliação da efetividade das políticas públicas voltadas para a proteção das áreas de captação de água são importantes no processo de gerenciamento dos recursos hídricos. O presente artigo tem o objetivo de analisar as diretrizes do plano diretor do município de São Carlos-SP direcionadas à proteção das captações de águas subterrâneas e superficiais outorgadas para o abastecimento público. Foram analisados Plano Diretor Estratégico (vigente) e o Plano Diretor de 2005 (vigente até 2016), para verificar se estes especificam diretrizes que visam à proteção dos poços e aquíferos importantes ao abastecimento público. As coordenadas geográficas dos locais de captação de água foram plotadas no software ArcGIS, no intuito de realizar sua sobreposição com os tipos de usos do solo presentes na região. Com base no Plano Diretor verificou-se que o mesmo delibera ações pontuais e não específicas no que se refere a proteção dos pontos de captações de água subterrânea e superficial. As Captações subterrâneas apresentam maiores concentrações de pontos de coleta na região centro-sul do município, especialmente em área de cana de açúcar e na área urbana. Apesar do Atlas Águas subterrâneas do Estado de São Paulo definir diretrizes específicas para a gestão e utilização dos recursos hídricos subterrâneo, não foi verificado ações de planejamento por parte do poder público de São Carlos-SP visando o monitoramento, fiscalização e proteção das captações dos recursos hídricos.
\end{abstract}

Abstract

Studies related to the evaluation of the effectiveness of public policies aimed at the protection of water catchment areas are important in the process of water resources management. The aim of this article is to analyze the directives of the master plan of the municipality of São Carlos-SP oriented to the protection of the catchments of groundwater and superficial water for the public supply. The Strategic Master Plan (current) and the Master Plan (in force from 2005 until 2016) were analyzed to verify if they specify guidelines that aim to protect the wells and aquifers that are important to the public supply. The geographic coordinates of the water catchment sites were plotted in the ArcGIS software, in order to overlap with the land use types, present in the region. Both Master Plans only deliberate punctual but not specific actions regarding the protection of groundwater and surface water catchment points. The underground catchment presents higher concentrations of collection points in the center-south region of the municipality, especially in the sugarcane area and in the urban area. The São Paulo State Groundwater Atlas define specific guidelines for the management and utilization of groundwater resources, but no planning actions have been carried out by São Carlos-SP aiming at the monitoring, control and protection of resources water resources.

DOI: http://dx.doi.org/10.14295/ras.v32i1.28977

\section{INTRODUÇÃO}

Atualmente mais da metade da população mundial reside em áreas urbanas (54\%) e esse número, segundo estudos, tende a aumentar, estima-se que em 2050, 66\% da população mundial habitará áreas urbanas (ONU, 2015).

Um dos maiores desafios, associados com a magnitude e velocidade de mudança da paisagem urbana, será a de fornecer água. Com o aumento da densidade populacional, a água adicional para o abastecimento da população deve ser organizada a partir de fontes situadas fora dos limites geográficos das cidades e em aquíferos (LUNDQVIST et al., 2003).
Além do crescimento populacional, outro fator que pode impactar no abastecimento de água são as mudanças climáticas, devido as alterações da frequência de chuvas e da severidade das secas. Estimativas sugerem que 3,1 bilhões de habitantes urbanos vão enfrentar falta sazonal de água até 2050 e que quase um bilhão delas sofrerão com a escassez perpétua (MCDONALD et al., 2011).

A relação entre urbanização e vulnerabilidade da água vem sendo alvo de diversos debates. Uma visão otimista, geralmente apoiada por engenheiros e hidrólogos (MEINZEN-DICK; APPASAMY, 2002; LUNDQVIST et al., 2003), argumenta que o abastecimento de água urbana é raramente limitado pela falta de recursos hídricos, e sim devido ao aumento da degradação de mananciais e através da atri- 
buição de recursos para utilizações agrícolas e industriais (ROSAN; RUBLE; TULCHIN, 2000).

Em contrapartida, diagnósticos realizados por geógrafos e urbanistas, expõe que muitos centros urbanos não serão capazes de expandir a oferta de recurso hídricos para atender à demanda, isso devido a uma gestão inadequada entre as agências relevantes (VO, 2007).

Com isso além de limitar o adensamento populacional, a gestão inadequada e o consequente déficit de recursos hídricos podem retardar o desenvolvimento e restringir a urbanização, um limiar de base da capacidade de suporte que alguns chamam de " restrição por recursos hídricos " (BAO; FANG, 2007).

Outro fator preocupante é o crescimento das cidades sem infraestrutura de fornecimento de água, que podem torná-las dependentes da utilização de água subterrânea (GUNERALP, 2008; VO, 2007).

De acordo com Tundisi et al., (2014), a média atual de perfurações de poços outorgados no Brasil é de 10.800 por ano. Contudo, há ainda pouco conhecimento da hidrodinâmica dos aquíferos no Brasil, e a principal deficiência para gestão adequada das águas subterrâneas é a carência de dados básicos sobre a favorabilidade hídrica e seu potencial de exploração, o que dificulta a elaboração de planos de gestão atual e futura. (HIRATA et al., 2010).

Além disso as avaliações e fiscalizações quantitativas da vulnerabilidade e do nível dinâmico dos aquíferos continuam a ser pouco incisivas as quais não têm considerado os impactos da urbanização em suas diversas escalas de abrangência (SRINIVASAN et al., 2012).

Os diversos usos da água devem ser levados em conta na avaliação para enquadramento e liberação para o uso dos recursos hídricos (SILVA; MONTEIRO, 2004). Deve-se também considerar as atividades humanas no entorno das captações de água, uma vez que essas podem acarretar erosões, sedimentação dos corpos de água, contaminação e poluição em larga escala, afetando a dinâmica dos ciclos hidrológicos. (VÖRÖSMARTY et al., 2010; YOUNG et al., 2014).

A expansão urbana e a diversificação dos usos múltiplos da água marcaram definitivamente as últimas décadas do século XX. Produção de alimentos, hidroeletricidade, navegação, recreação, agricultura, abastecimento público são usos competitivos da água, para os quais são necessárias governança efetiva, estratégia integrada e definição de prioridades. (TUNDISI; MATSUMURA, 2015).

Nesse sentido, o gerenciamento de recursos hídricos é uma necessidade fundamental e tem o objetivo de ajustar as demandas econômicas, sociais e ambientais por água em níveis sustentáveis, de modo a permitir, sem conflitos, a convivência dos usos atuais e futuros da água (CAMPOS; FRACALANZA, 2010).

Por esses motivos, cabe ao Poder Público, estadual ou federal, a responsabilidade pela sua gestão. Em outras palavras, qualquer intervenção em um corpo de água é passível de autorização por parte do Poder Público competente. À luz da legislação vigente, essa autorização é denominada de Outorga de Direito de Uso de Recursos Hídricos (SILVA; MONTEIRO, 2004).

Desta forma, o presente artigo tem o objetivo de analisar as diretrizes do plano diretor do município de São Carlos-SP direcionadas à proteção das captações de águas subterrâneas e superficiais outorgadas para o abastecimento, devido ao potencial de contaminação dos recursos hídricos a qual a região está inserida, além de analisar o uso e ocupação do solo a fim de diagnosticar as pressões antrópicas exercidas sobre os recursos hídricos.

\section{METODOLOGIA}

\section{1 Área de Estudo}

A área de estudo abrange o município de São Carlos, o qual está localizado na região central do estado de São Paulo, distante $228 \mathrm{~km}$ da capital, entre as coordenadas $48^{\circ} 5^{\prime} 27,6^{\prime \prime}$ e $47^{\circ} 43^{\prime} 8,4^{\prime \prime}$ longitude oeste e $21^{\circ} 35^{\prime} 50,7^{\prime \prime}$ e; $22^{\circ} 9$ '39,7" de latitude sul.

O município possui $1.138 \mathrm{~km}^{2}$ de extensão, sendo $672 \mathrm{~km}^{2}$ correspondentes à área urbana (Figura 1). A população em 2018 é de 241.389 habitantes, com Índice de Desenvolvimento Humano Municipal-IDHM de 0,805 (IBGE, 2017). 0 território do município, está situado em duas Unidades de Gerenciamento de Recursos Hídricos - UGRHI 13 - Tietê-Jacaré e UGRHI 9 - Mogi Guaçu.

O clima é classificado como Tropical Úmido-Seco (Cwa), de inverno seco e verão chuvoso (MENDONÇA; DANNI-OLIVEIRA, 2007) a precipitação média anual entre os anos de 1977 a 2006 foi de $1.490 \mathrm{~mm}$ por ano, havendo uma nítida distinção de pluviosidade entre os meses mais secos (maio a agosto) e os meses mais chuvosos (setembro a abril), com média mensal de $37,8 \mathrm{~mm}$ e $167 \mathrm{~mm}$ respectivamente, sendo o mês mais chuvoso janeiro $(264 \mathrm{~mm})$ e o mês com menos chuva julho (23mm) (MARCUZZO, 2017).

A geologia do município distribui-se em terrenos da Formação Botucatu (51\% - 577.57 km²), composto essencialmente por arenitos. As unidades Intrusivas Básicas Tabulares ocupam 198.44km² (17\%), em especial na porção norte, onde aparecem sob a forma de Diques e Sills. As formações Itaqueri, Pirambóia, Corumabatí e os Depósitos Aluvionáres e Colúvios-eluvionares também estão presentes na área de estudo (CPRM, 2006; MURO, 2000; CPA 2017).

Segundo o "Atlas Águas subterrâneas no Estado de São Paulo: Diretrizes de Utilização e Proteção" (DAEE/LEBAC, 2013), São Carlos enquadra-se na categoria Alta do Índice de Potencial Poluidor e Áreas Contaminadas, devido a quantidade de empreendimentos licenciados pela CETESB, com base no potencial de fontes poluidoras sugerido pelo método POSH (Pollutant Origin, Surcharge Hydraulically). 
Figura 1- Localização do munícipio de São Carlos-SP

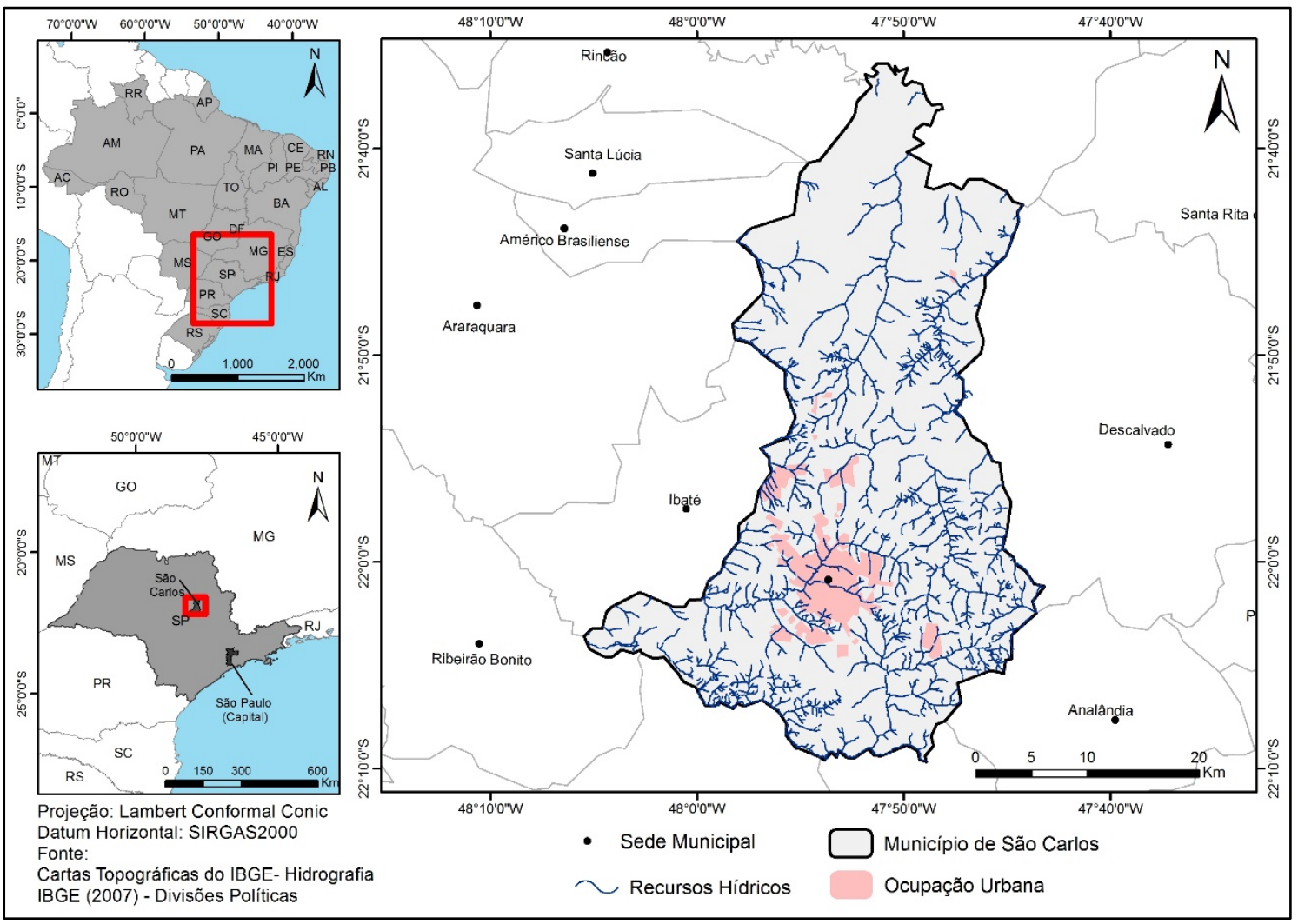

O município é enquadrado como "Município instalado em áreas com restrições", onde as utilizações dos recursos hídricos subterrâneos devem seguir uma série de orientações específicas de gestão e uso racional (DAEE/LEBAC, 2013).

Dentre estas diretrizes destacam-se a Proteção das captações de água subterrânea visando à proteção dos poços e aquíferos importantes ao abastecimento público; o Cadastramento, controle e fiscalização das captações das outorgas de uso da água subterrânea e a consolidação e a participação dos municípios na gestão dos recursos hídricos.

\subsection{Material e Métodos}

As informações acerca do compartimento abiótico e biótico presentes no município de São Carlos foram inseridas e analisadas em Sistemas de Informações Geográficas (SIGs), na projeção geográfica de Universal Transversa de Mercator, Fuso 23 Sul, datum SIRGAS 2000, utilizando-se o software ArcGis 10.5.

A malha digital dos municípios brasileiros para a delimitação do município de São Carlos foi adquirida da base de dados digital do Instituto Brasileiro de Geografia e Estatística-IBGE, versão 2015. Para a obtenção da rede de drenagem, foram adquiridas as cartas planialtimétricas do IBGE em formato analógico na escala 1:50.000, referente as folhas: SF-22-Z-B-III-2, SF-23-V-C- IV-1, SF-23-V-C- IV-3, SF-23-Y-A- I-1, SF-23-V-C- IV-2, SF-23-V-C-IV-4 e SF-23-Y-A-I-2.

O mapa de Unidades geológicas foi gerado a partir da análise e compilação do mapeamento elaborado por MURO (2010) na escala de 1:50.000 e do mapa de Unidades Básicas de Compartimentação do Meio Físico do Estado de São Paulo (CPA,2017).
Para classificação do uso e ocupação do solo foi utilizada a cena referente ao satélite LandSat 8 - sensor OLI/TIRS, correspondente à órbita/ponto 220/75, com data de passagem em 30 de abril de 2017.

A classificação dos usos e cobertura da terra foi baseada no sistema multinível proposto pelo Manual Técnico de Uso da Terra (IBGE, 2013), que no nível hierárquico primário (I), contemplou quatro classes que indicaram as principais categorias da cobertura terrestre, discriminadas com base na interpretação direta dos dados dos sensores remotos, numa escala mais ampla.

Foram analisados o atual Plano Diretor Estratégico (SÃO CARLOS, 2016) e o Plano Diretor de 2005 (vigente até dezembro de 2016) (SÃO CARLOS, 2005), para verificar se estes especificam diretrizes que visam à proteção dos poços e aquíferos importantes ao abastecimento público.

Os dados de outorga de captação de água superficial e subterrânea, o volume de água outorgado, as categorias de usos dos recursos hídricos e suas finalidades, foram levantados junto ao Departamento de Águas e Energia Elétrica (DAEE) (DAEE, 2017) vinculado ao Governo do Estado de São Paulo e aos bancos da Rede Integrada de Monitoramento das Águas Subterrâneas (RIMAS) (CPRM, 2017a) e do Sistema de Informações de Águas Subterrâneas (SIAGAS) (CPRM, 2017b) ambos do Serviço Geológico do Brasil (CPRM).

As planilhas eletrônicas, contendo as coordenadas geográficas dos locais de captação de água foram plotadas no software ArcGIS, transformadas em shapefiles e delimitadas para a região do município no intuito de realizar sua sobreposição com os tipos de usos do solo presentes na região. 
Para a análise considerou-se apenas os pontos de captação com status: Implantação autorizada; Licença de funcionamento; Licença de perfuração e implantação; Serviço autorizado; Portaria.

Os pontos com outorgas em situação irrelevantes, como pontos tamponados e licenças revogadas ou indeferidas foram desconsiderados, uma vez que não estão em funcionamento ou sequer foram instalados. Essas informações foram sobrepostas ao uso e cobertura da terra de 2017, para verificar quais usos estão presentes no entorno dos pontos de captação.

\section{RESULTADOS}

Com base na análise do Plano Diretor verificou-se que o mesmo delibera ações pontuais e não específicas no que se refere a proteção dos pontos de captações de água subterrânea e superficial (SÃO CARLOS, 2016).

Tais ações são verificadas no Capítulo I - Dos Objetivos Gerais do ordenamento territorial, art. $3^{\circ}-\mathrm{X}$ : "proteger as áreas de preservação permanente, as unidades de conservação, as áreas de proteção dos mananciais e a biodiversidade; " e nas seguintes seções:

Seção VI- DA ZONA 5 - PROTEÇÃO E OCUPAÇÃO CONTROLADA. Art. 31. II - preservar e proteger os principais pontos de captação de água do Município;

SEÇÃO XII DA ZONA 8A: PROTECCÃO E OCUPAÇÃO RESTRITA DO MONJOLINHO-ESPRAIADO Art. 59. A Zona 8A: I - preservar e proteger o manancial do Monjolinho-Espraiado, um dos principais pontos de captação de água do Município; SEÇÃO XIII DA ZONA 8B - ZONA DE PROTEÇÃO DO MANANCIAL DO RIBEIRÃO FEIJÃO Art. 63. A Zona 8B: I - preservar e proteger o manancial do Ribeirão do Feijão, um dos importantes pontos de captação de água do Município;

Comparando o Plano Diretor vigente a partir de 2016 (SÃO CARLOS, 2016) com o Plano Diretor datado de 2005 (SÃO CARLOS, 2005), verificou-se que houve um retrocesso nas diretrizes referentes às ações analisadas, uma vez que o Plano Diretor de 2005 previa em seus textos diretrizes específicas para a proteção de áreas utilizadas para fins de captações de águas de abastecimento potáveis. Tais ações estavam designadas no Título II Do Ordenamento Territorial do Município - Capítulo 1 - Das Diretrizes Gerais - Art. 14:

o Macrozoneamento e o Zoneamento do Município deverão atender às seguintes diretrizes:

IV - designar as unidades de conservação ambiental e outras áreas protegidas por Lei, discriminando as de preservação permanentes ou temporárias, nas encostas, nas bordas de tabuleiros ou chapadas ou, ainda, nas áreas de drenagem das captações utilizadas ou reservadas para fins de abastecimento de água potável e estabelecendo suas condições de utilização;

No Título III- Do Parcelamento, Uso e Ocupação do Solo; Capítulo I-
Parcelamento do Solo, Art. 103:

0 projeto de drenagem constituído por poços de infiltração, bacias de retenção de águas pluviais, dispositivos de dissipação de energia, pavimentos permeáveis e demais componentes do sistema, devem ser concebidos e implantados de tal modo que a vazão de escoamento seja mantida dentro das condições originais da área antes de ser urbanizada, reduzindo-se o impacto da urbanização nos fundos de vale e nos corpos d'água.

Os dados do DAEE relativos à outorga de captação de água superficial, subterrânea e em nascentes permitiram a análise da distribuição espacial, bem como a quantificação da outorga de água na região de estudo.

O volume total de captações cadastrado junto ao DAEE (DAEE, 2017), RIMAS (CPRM, 2017a) e SIAGAS (CPRM, 2017b) é de $11398.8 \mathrm{~m}^{3} / \mathrm{h}$, distribuído em 468 pontos de captações subterrâneas $\left(6730.82 \mathrm{~m}^{3} / \mathrm{h}\right.$ - cerca de $\left.59.05 \%\right), 111$ pontos de captações superficiais que representa $41.16 \%\left(4662 \mathrm{~m}^{3} / \mathrm{h}\right)$, e 14 pontos de captações em nascentes que correspondem a aproximadamente $0.04 \%\left(5 \mathrm{~m}^{3} / \mathrm{h}\right)$. A finalidade dos usos da água, em sua maioria, refere-se ao abastecimento público e privado representando quase $80 \%$ do volume total (Tabela 1 ).

Embora os usos do solo predominantes no município estejam relacionados às atividades agropastoris (cultivo de cana de açúcar, pastagem, silvicultura) (Figura 2) a captação da categoria "Uso Rural" representa apenas $7.12 \%$ do volume total captado.

No entanto, apesar do baixo volume captado essas atividades podem comprometer a qualidade e quantidade dos recursos hídricos. Merten; Minella (2002) afirmam que a qualidade da água é um reflexo do uso e manejo do solo, sendo a atividade agropecuária considerada com potencial degradador, devido a sua capacidade de poluição difusa por meio de deflúvio superficial, lixiviação e fluxo de contaminantes ou pontual por lançamento direto no ambiente.

O estudo realizado por Dalin et al., (2017) demonstrou que as modificações hidrológicas recentes se devem principalmente a retirada de águas subterrânea para irrigação. Dentre as principais atividades agropecuárias listadas no estudo, destacam-se o cultivo de cana de açúcar e forragem, as quais são usos do solo dominantes no município.

Cerca de $50 \%$ das captações superficiais estão concentradas nos mananciais do Feijão e do Monjolinho, estando predominantemente localizados em áreas de cultivos de cana de açúcar (55 pontos de captação) e em área urbanizada (28 pontos de captação). 
Tabela 1 - Categorias de uso das captações outorgadas no município de São Carlos.

\begin{tabular}{|c|c|c|c|c|c|c|c|c|}
\hline \multirow[t]{2}{*}{ Categoria } & \multicolumn{2}{|c|}{ Captação Subterrânea } & \multicolumn{2}{|c|}{ Captação Superficial } & \multicolumn{2}{|c|}{$\begin{array}{l}\text { Captação em Nas- } \\
\text { centes }\end{array}$} & \multicolumn{2}{|c|}{ Captação Total } \\
\hline & $\mathrm{m}^{3} / \mathrm{h}$ & $\%$ & $\mathrm{~m}^{3} / \mathrm{h}$ & $\%$ & $\mathrm{~m}^{3} / \mathrm{h}$ & $\%$ & $\mathrm{~m}^{3} / \mathrm{h}$ & $\%$ \\
\hline Uso Rural & 479 & 7.12 & 791 & 17 & 4 & 80 & 12740 & 11.18 \\
\hline Uso Industrial & 1053.83 & 15.66 & 110 & 3 & & & 1163.83 & 10.21 \\
\hline Mineração & 6 & 0.09 & 90 & 2 & & & 96 & 0.84 \\
\hline $\begin{array}{l}\text { Abastecimento Pú- } \\
\text { blico }\end{array}$ & 3506.49 & 52.1 & 3631 & 77 & 1 & 20 & 713849 & 62.62 \\
\hline $\begin{array}{l}\text { Abastecimento Pri- } \\
\text { vado }\end{array}$ & 1685.5 & 25.04 & 41 & 1 & & & 1726.5 & 15.15 \\
\hline Total & 6730.82 & 100 & 4.692 & 100 & 5 & 100 & 11398.8 & 100 \\
\hline
\end{tabular}

Segundo Costa (2010) os dois mananciais estão entre os vetores de crescimento da mancha urbana e em áreas com uso intensivo do solo devido a atividades como pecuária e cultura de cana-de-açúcar, ou seja, usos que necessitam de um grande volume de água e que são fontes de poluição.

Costa et al., (2015), destaca que um dos principais desafios enfren- tados por gestores públicos é a manutenção da quantidade e qualidade da água disponível para o consumo. Desta forma, para garantir a quantidade e qualidade da água captada é essencial a proteção desses pontos de coleta, principalmente, respeitando as áreas de preservação permanente delimitadas pela Lei $n^{\circ} 12.651$ (BRASIL, 2012).

Figura 2- Distribuição das captações outorgadas e usos do solo no município de São Carlos

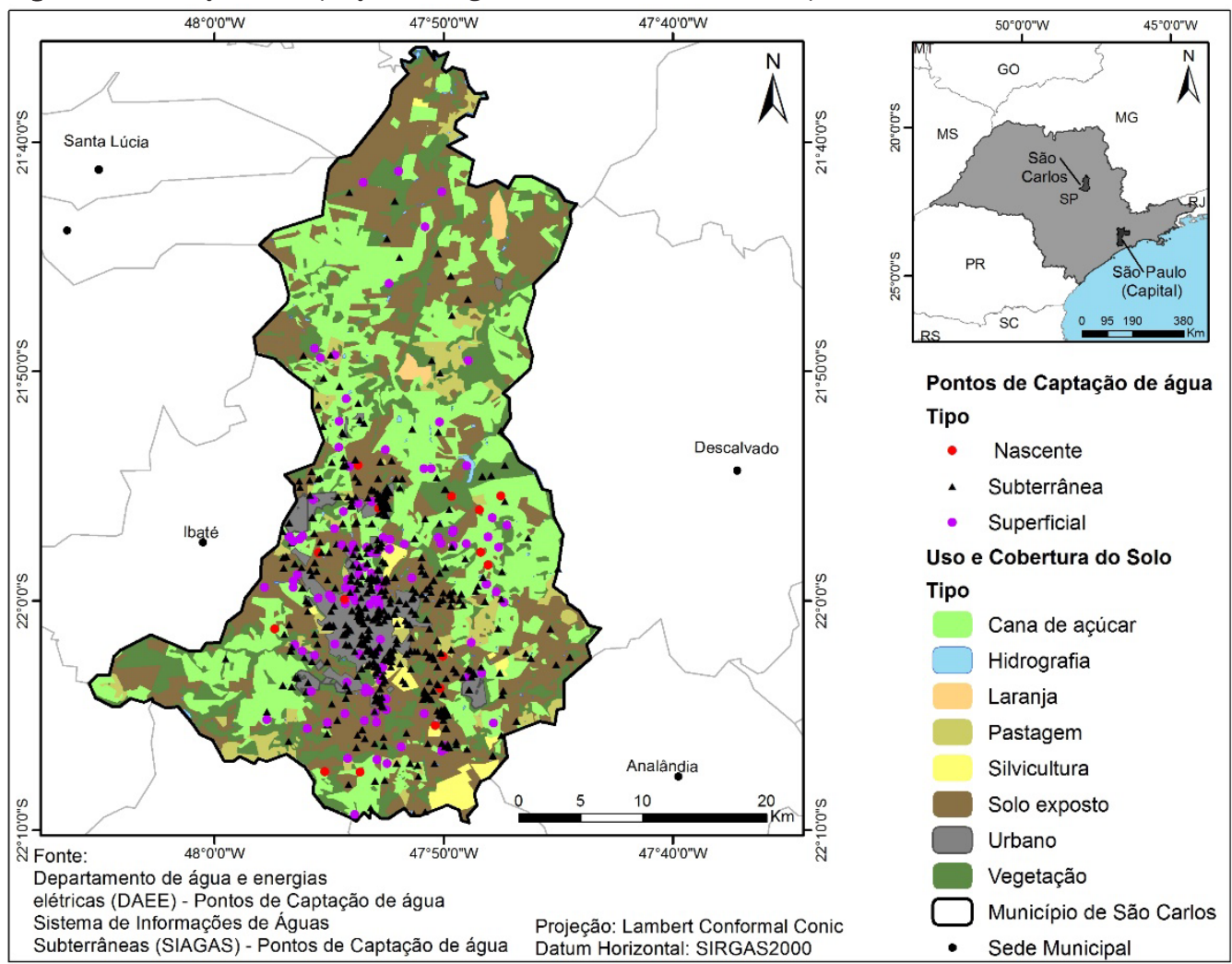

A preservação das matas ciliares influencia diretamente nos custos dispensados para o tratamento da água captada. 0 custo para tratar $1.000 \mathrm{~m}^{3}$ pode variar de $\mathrm{R} \$ 2,00$ a $\mathrm{R} \$ 300,00$ dependendo da preservação das matas ciliares (TUNDISI, 2010).

As captações subterrâneas apresentam maiores concentrações de pontos de coleta na região centro-sul do município, especialmente em área de cultivos de cana de açúcar (210 poços) e área urbana (190 poços), enquanto que apenas 37 poços estão protegidos por vegetação nativa.

Isso demonstra um cenário de vulnerabilidade das águas subterrânea, devido à existência de poços não protegidos, localizados em áreas potenciais à contaminação devido ao uso de insumos agrícolas de natureza biológica ou química e atividades urbanas, como indústrias e postos de combustíveis (Figura 2 e Tabela 2).

Sobretudo em virtude da existência dessas atividades, principalmente, nas Formações Botucatu (154 poços) e Itaqueri (99 poços) (Figura 3), que por suas características possuem maior vulnerabilidade à poluição das águas subterrâneas, devido às suas composições arenosa e porosa, facilitando a percolação dos poluentes (CARNEIRO, 2007). Além disso, tais formações configuram-se em aquíferos sedimentares, com alta transmissividade e, consequentemente com baixa capacidade de mitigação dos poluentes (COSTA, 2017). 
Os afloramentos da formação Botucatu compões o Sistema de Aquíferos Guarani, o qual é uma grande reserva de água doce internacional abrangendo o Brasil, Argentina, Paraguai e Uruguai (OLIVEIRA et al., 2016). Portanto, é de extrema importância o controle da perfuração e proteção dos poços nessa região, por meio de restrições de atividades potencialmente poluidoras nas proximidades, bem como, o tamponamento adequado dos poços não utilizados.

O volume de água captado em nascente é pouco representativo se comparado aos demais tipos de captações. São captados $5 \mathrm{~m}^{3} / \mathrm{h}$, sendo que $80 \%$ são destinados ao uso rural, $20 \%$ ao abastecimento público.

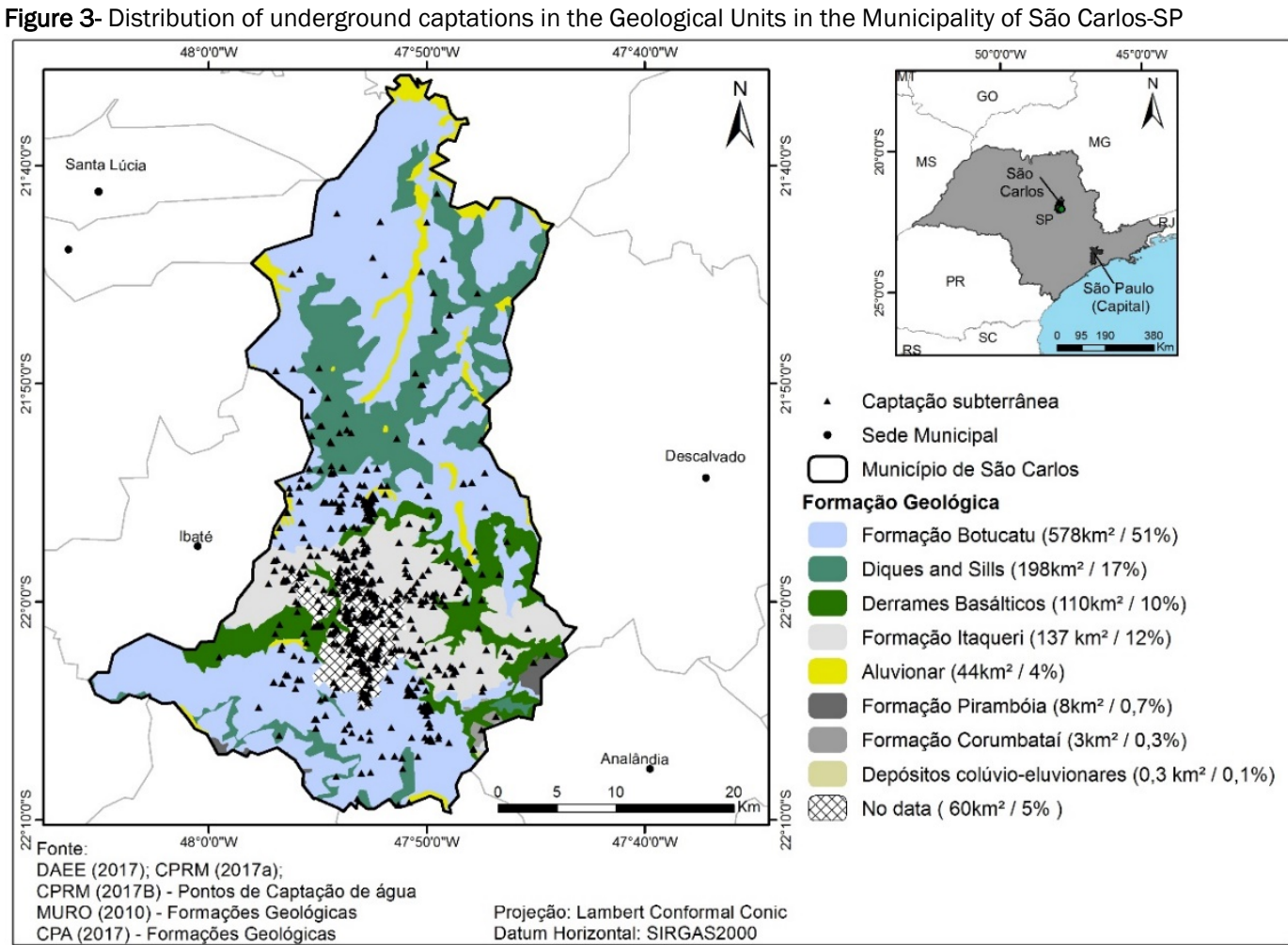

Tabela 2- Distribuição dos pontos de captação atrelado ao Uso e cobertura do solo do município de São Carlos (SP) para 2017

Tabela 2- Distribuição dos pontos de captação atrelado ao Uso e cobertura do solo do municipio de São Carlos (SP) para 2017

\begin{tabular}{|c|c|c|c|c|c|}
\hline & Área (ha) & $\%$ & & & \\
\hline Áreas Urbanizadas & $7.012,83$ & 6,15 & 3 & 190 & 28 \\
\hline Cana-de-açúcar & $36.955,48$ & 32,42 & 3 & 64 & 31 \\
\hline $\begin{array}{l}\text { Solo preparado para o } \\
\text { plantio/pousio (Cana-de- } \\
\text { açúcar) }\end{array}$ & $38.692,85$ & 33,94 & 7 & 157 & 24 \\
\hline Citricultura & 711,04 & 0,62 & 0 & 0 & 0 \\
\hline Pastagem & $5.662,18$ & 4,97 & 0 & 17 & 6 \\
\hline Silvicultura & $2.065,73$ & 1,81 & 0 & 10 & 0 \\
\hline Vegetação Nativa & $22.018,44$ & 19,31 & 1 & 37 & 17 \\
\hline Corpos Hídricos & 841,45 & 0,74 & 0 & 1 & 1 \\
\hline TOTAL & 841,45 & 100 & 14 & 431 & 107 \\
\hline
\end{tabular}

Fonte: Autores

\section{CONSIDERAÇÕES FINAIS}

Apesar do Atlas Águas subterrâneas do Estado de São Paulo definir diretrizes e orientações específicas para a gestão e utilização dos recursos hídricos subterrâneo, não foi verificado ações de planejamento por parte do poder público municipal de São Carlos-SP visando o monitoramento, fiscalização e proteção das captações subterrâneas. 0 mesmo ocorre com a captação de águas superficiais e 
em nascentes. Isso pode ser constatado na falta de diretrizes no Plano Diretor Estratégico e no tipo de uso do solo encontrados ao redor das captações.

Sendo assim, os serviços ecossistêmicos, relacionados à provisão de recursos, podem ser prejudicados, implicando na perda das funções ambientais e consequentemente nos benefícios que estas proporcionam à população, como a disponibilidade de água em quantidade e qualidade, bem como a recarga de águas subterrânea.

Diante desse fato, torna-se necessário um planejamento integrado que almeje um modelo de desenvolvimento que leve em consideração toda esta temática, incluindo os agentes socioambientais e econômicos, focando não apenas nos problemas, mas em suas causas, reforçando a ideia de necessidade de desenvolvimento que relacione o crescimento econômico e a conservação dos ecossistemas.

Vale ressaltar, que os dados disponibilizados pelo DAEE e CPRM em relação às outorgas concedidas podem não condizer com a realidade devido a existência de captações clandestinas e de usuários que não respeitam o volume outorgado excedendo seu limite, o que pode tornar o cenário ainda mais preocupante no que diz respeito ao nível estático dos aquíferos e a qualidade e quantidade dos recursos hídricos, sejam eles subterrâneos ou superficiais.

\section{AGRADECIMENTOS}

Os autores agradecem a Coordenação de Aperfeiçoamento de Pessoal de Nível Superior e a Fundação de Amparo à Pesquisa do Estado de São Paulo processo 2015/19918-3 pelo apoio a pesquisa.

\section{REFERÊNCIAS}

BRASIL. Lei $n^{\circ} 12.651$, de 25 de maior de 2012. Dispõe sobre a proteção da vegetação nativa, Brasília, DF, 2012. Disponível em: <http://www.planalto.gov.br/ccivil_03/_ato2011-2014/2012/lei/l12651.htm>. Acesso em: 10 de janeiro de 2018.

BRASIL. Departamento de águas e Energia Elétrica. Secretaria de Saneamento e Recursos Hídricos. Relatório de Recursos Hídricos cadastrados e outorgados pelo DAEE. 2016. Disponível em: <http://www.aplicacoes.daee.sp.gov.br/usosrec/fchweb.html>. Acesso em: 24 de novembro de 2017.

BAO, C.; FANG, C. L. Water resources constraint force on urbanization in water deficient regions: a case study of the Hexi Corridor, arid area of NW China. Ecological Economics. v.62, n.3-4, p.508-517, 2007. Disponível em $<$ https://www.sciencedirect.com/science/arti-

cle/pii/S0921800906003466>. Acesso em 27 de março de 2017.

CARNEIRO C. D. R. Viagem virtual ao Aquífero Guarani: Formações Pirambóia e Botucatu, Bacia do Paraná. Terra Didatica, v.3, n.1, p.50-73, 2008. Disponível em < https://periodicos.sbu.unicamp.br/ojs/index.php/td/article/view/8637476>. Acesso em 27 de março de 2017.

COSTA, C. W. Expansão da mancha urbana e suas consequências sobre os mananciais do Rio do Monjolinho e do Ribeirão do Feijão da cidade de São Carlos, SP. 2010, 141f. Dissertação (Mestrado em Meio ambiente e Recursos Hídricos). Universidade Federal de São Carlos, São Carlos, 2010.

COSTA, C. W.; PIGA, F. G.; MORAES, M. C. P., DORICI, M.; SANGUINETTO, E. C.; LOLLO, J. A.; MOSCHINI, L. E.; LORANDI, R.; OLIVEIRA, L. J. Fragilidade ambiental e escassez hídrica em bacias hidrográficas: Manancial do Rio das Araras - Araras, SP. Revista Brasileira de Recursos Hídricos, v. 20 n.4, Porto Alegre, p.946 - 958. 2015. Disponível em $<$ https://www.abrh.org.br/SGCv3/index.php?PUB=1\&ID=156\&SUMA$\mathrm{RIO}=512>$.Acesso em 27 de março de 2017.
COSTA, C. W. Mapeamento geoambientais, em escala 1:50.000, aplicados em análises de planejamento territorial de manancial periurbano: bacia do Ribeirão do Feijão, São Carlos, SP. 2017, 152f. Tese (Doutorado em Ciências Ambientais), Universidade Federal de São Carlos, São Carlos, 2017.

CPA. Coordenadoria de Planejamento Ambiental do estado de São Paulo, Unidades Básicas de Compartimentação do Meio Físico do Estado de São Paulo. São Paulos, 2017. Disponível em < http://www.ambiente.sp.gov.br/cpla/cessao-de-dados/ > Acesso em 27 de março de 2017.

CPRM. Serviço Geológico do Brasil. Mapa Geológico do Estado de São Paulo, 2006. CPRM, v.2, 173p. Disponível em: <http://www.aplicacoes.daee.sp.gov.br/usosrec/fchweb.html>. Acesso em: 24 de novembro de 2017.

CPRM. Serviço Geológico do Brasil . Rede Integrada de Monitoramento das Águas Subterrâneas - RIMAS. Rio de Janeiro, 2017a. Disponível em: <http://rimasweb.cprm.gov.br/layout/index.php>. Acesso em: 22 janeiro de 2018.

CPRM. SERVIÇO GEOLÓGICO DO BRASIL. Sistemas de Informações de Águas Subterrâneas - SIAGAS. Rio de Janeiro, 2017b. Disponível em: < http://siagasweb.cprm.gov.br/layout/>. Acesso em: 22 janeiro de 2018.

DAEE/LEBAC. Águas subterrâneas no Estado de São Paulo. Diretrizes de Utilização e Proteção/Departamento de Águas e Energia Elétrica, Instituto Geociências e Ciências Exatas. Laboratório de Estudo de Bacias. - São Paulo, p. 44. 2013.

DAEE. Departamento de Águas e Energia Elétrica. Outorgas de captação de água para o estado de São Paulo. São Paulo, 2017. Disponível em: < http://www.daee.sp.gov.br>. Acesso em 22 de janeiro de 2018.

DALIN, C.; WADA, Y.; KASTNER, T.; PUMA, M.J. Groundwater depletion embedded in international food trade. Nature. v.543, p.700-704, 2017. Disponível em: < https://www.nature.com/articles/nature21403 >. Acesso em 22 de janeiro de 2018 .

GUNERALP, B. Environmental impacts of urban growth from an integrated dynamic perspective: a case study of Shenzhen, South China. Global Environmental Change. v.18, p.720-735, 2008. Disponível em: $<$ https://www.sciencedirect.com/science/article/pii/S0959378008000587>. Acesso em: 3 janeiro. 2018.

HIRATA, R.; ZOBY, J. L. G.; OLIVEIRA, F. R. Água Subterrânea: Reserva estratégica ou emergencial. In: BICUDO, C. E. M.; TUNDISI, J.G.; Scheuenstuhl, M.C.B. (orgs.). Águas no Brasil: Análises estratégicas. Academia Brasileira de Ciência, São Paulo: Instituto de Botânica, 149-161. 2010. Disponível em: <https://www.agrolink.com.br/downloads/\%C3\%A1gua\%20subterr\%C3\%A2nea\%20-\%20reserva\%20estrat\%C3\%A9gica\%20ou\%20emergencial.pdf >. Acesso em: 3 janeiro. 2018.

IBGE. Censo Demográfico, 2000. Disponível em: <https://www.ibge.gov.br/estatisticas-novoportal/sociais/educacao/9663censo-demografico-2000.html?edicao=9771 >. Acesso em 23 de setembro de 2017.

IBGE. Censo Demográfico, 2010. Disponível em: <http://censo2010.ibge.gov.br/pt/>. Acesso em 23 de setembro de 2017.

IBGE. IBGE Cidades, 2017. Disponível em: <https://cidades.ibge.gov.br/brasil/sp/sao-carlos/panorama>. Acesso em 21 outubro de 2017.

IBGE. Instituto de Geografia e Estatística. Manual técnico de uso da terra. 3. ed. 2013. Disponível em: < www.ibge.gov.br/home/geociencias/recursosnaturais/usodaterra/manual_usodaterra.shtm>. Acesso em: 31 de maio de 2017.

IRITANI, M., A.; EZAKI, S. As águas subterrâneas do Estado de São Paulo. 2. ed. São Paulo. Secretaria de Estado do Meio Ambiente - SMA, 104p. 2009. Disponível em: <http://www.igeologico.sp.gov.br/downloads/livros/cart_AG_SB.pdf>. Acesso em: 3 jan. 2018.

LUNDQVIST, J.; APPASAMY, P.; NELLIYAT, P. Dimensions and approaches for Third World city water security. Biological Sciences, v.358, n.1440, p.19851996, 2003. Disponível em: < https://www.ncbi.nlm.nih.gov/pubmed/14728793>. Acesso em: 3 jan. 2018. 
MARCUZZO, F. F. N. Mapas de chuva espacializada mensal e anual no território do município de São Carlos/SP. In: SIMPÓSIO BRASILEIRO DE RECURSOS HÍDRICOS, 22., 2017, Florianópolis. Anais... Florianópolis: ABRH, 2017. Disponivel em: <http://rigeo.cprm.gov.br/ispui/handle/doc/18486>. Acesso em: 3 jan. 2018

MCDONALD, R.I.; GREEN, P.; BALK, D.; FEKETE, B.M.; REVENGAA, C., TODD, M.; MONTGOMERY, M. Urban growth, climate change, and freshwater availability. Proceedings of the National Academy of Sciences v. 108, n.15, p.6312-6317, 2011. Disponivel em: <http://www.pnas.org/content/108/15/6312.abstract >. Acesso em: 3 jan. 2018.

MEINZEN-DICK, R.; APPASAMY, P. P. Urbanization and intersectoral competition for water. Woodrow Wilson International Center for Scholars Environmental Change and Security Project (ed.) Finding the Source: The Linkages Between Population and Water. Washington, DC, The Woodrow Wilson Institute, p.27-51, 2002.

MENDONÇA, F.; DANNI-OLIVEIRA, I. M. Climatologia: noções básicas e climas do Brasil. São Paulo: Oficina de Texto, v. 22, n.3, 206 p. 2007. Disponível em: <http://dx.doi.org/10.1590/S1982-4513201000030001>. Acesso em: 24 de novembro de 2017

MERTEN, G. H.; MINELLA, J. P. Qualidade da água em bacias hidrográficas rurais: um desafio atual para a sobrevivência futura. Agroecologia e Desenvolvimento Rural Sustententável. Porto Alegre, v.3, n.4, p.33-39, 2002. Disponível em: $<$ http://taquari.emater.tche.br/docs/agroeco/revista/ano3 n4/artigo2.pdf> Acesso em: 24 de novembro de 2017.

MURO, D. M. 2000. Zoneamento de áreas quanto a possivel contaminação por produtos químicos. 2000. 100 f. Dissertação (Mestrado em Geotecnia) - Escola de Engenharia de São Carlos da Universidade de São Paulo, ConseIho Nacional de Desenvolvimento Científico e Tecnológico, 2000.

OLIVEIRA, M. C.; JUNIOR, O. P. A.; FIORILLO, C. A. P.; COLENCI, P. L. Regulation of surface and subterranean fresh water in the MERCOSUR regional integration. Taubaté, Revista Ambiente e Água, v. 11 n. 2, p.20-26, 2016. Disponível em: <http://dx.doi.org/10.4136/ambi-agua.1666> Acesso em: 24 de novembro de 2017.

ONU. United Nations. World urbanization prospects the 2014 revision. 2015 , 514p. Disponível em: <https://esa.un.org/unpd/wup/> Acesso em: 24 de novembro de 2017.

ROSAN, C.; RUBLE, B. A.; TULCHIN, J. S. Urbanization, Population, Environment, and Security. A Report of the Comparative Urban Studies Project, Woodrow Wilson International Center for Scholars, Washington, DC, 104p. 2000. Disponível em: <http://citeseerx.ist.psu.edu/viewdoc/download;jsessio-

nid=19A3589A05A85D7E78941606463C4BE2?doi=10.1.1.578.8102\&re $\mathrm{p}=$ rep 1 \&type $=p d f>$. Acesso em: 24 de novembro de 2017 .

SÃO CARLOS. Lei no 13.691 de 25 de novembro de 2005 - Institui o Plano Diretor do Município de São Carlos e dá outras providências. 2005. Disponível em: < http://www.saocarlos.sp.gov.br/images/stories/pdf/Lei_13691_05_Plano_Diretor.pdf>. Acesso em: 24 de novembro de 2017.

SÃO CARLOS. Lei Nº 18.053 de 19 de dezembro de 2016, Institui o Plano
Diretor do Município de São Carlos e dá outras providências. 2016. Disponível em: <http://www.saocarlos.sp.gov.br/images/stories/pdf/2017/pde/lei18053\%20-\%20Plano\%20Diretor\%20-\%20digital.pdf>. Acesso em: 24 de novembro de 2017.

SÃo PAULO. Coordenadoria de Planejamento Ambiental do estado de São Paulo. Unidades Básicas de Compartimentação do Meio Físico do Estado de São Paulo, 2017. Disponivel em: <http://www.aplicacoes.daee.sp.gov.br/usosrec/fchweb.html>. Acesso em: 24 de novembro de 2017.

SILVA, L.M.C.; MONTEIRO, R.A. Outorga de direito de uso de recursos hídricos: uma das possíveis abordagens. In: MACHADO, C.J.S. (Org.). Gestão de águas doces: usos múltiplos, políticas públicas e exercício da cidadania no Brasil. Rio de Janeiro: Interciência. p.135-178, 2004. Disponível em:< http://143.107.108.83/sigrh/cobranca/pdf/leitura 04.pdf>. Acesso em: 20 de janeiro de 2018 .

SRINIVASAN, A.V.; SETO K.C.; EMERSON, R.; GORELICK S.M. The impact of urbanization on water vulnerability: A coupled human- environment system approach for Chennai, India. Global Environmental Change. v.23, p. 229 239, 2013. Disponível em: $<$ https://www.sciencedirect.com/science/article/pii/S095937801200115X>. Acesso em: 20 de janeiro de 2018.

TUNDISI, J.G.; TUNDISI, T.M. Impactos potenciais das alterações do Código Florestal nos recursos hídricos. Biota Neotropica, Campinas. v.10, n. 4, p. 67-76. 2010. Disponível em: <http://dx.doi.org/10.11606/issn.23169036.v0i106p21-30>. Acesso em: 20 de janeiro de 2018 .

TUNDISI, J.G.; SCHEUENSTUHL, M. C. B.; ALMEIDA CAMPOS, D.; FERNANDES, J.; TREVISAN, P.; VIEIRA, V. Recursos hídricos no Brasil: problemas, desafios e estratégias para o futuro. Academia Brasileira de Ciências, Rio de Janeiro, p. 90. 2014. Disponivel em: <http://www.abc.org.br/IMG/pdf/doc5923.pdf>. Acesso em: 20 de janeiro de 2018.

CAMPOS, V. N. de OLIVEIRA; FRACALANZA, A. P. Governança das águas no brasil: Conflitos pela apropriação da água e a busca da integração como consenso. Ambiente \& Sociedade, Campinas. v. 8, n. 2, p. 365-382, 2010. Disponível em: < http://www.scielo.br/pdf/asoc/v13n2/v13n2a10>. Acesso em: 20 de janeiro de 2018

VÖRÖSMARTY, C. J.; MCINTYRE, P. B.; GESSNER M. O.; DUDGEON, D.; PRUSEVICH, A.; GREEN, P.; GLIDDEN, S.; BUNN, S. E.; SULLIVAN, C. A.; REIDY LIERMANN, C.; DAVIES, P. M. "Global Threats to Human Water Security and River Biodiversity". Nature, v 467, n 7.315, p. 555-61, 2010. Disponível em: <https://www. nature.com/articles/nature09440/metrics>. Acesso em: 20 de janeiro de 2018.

VO, P. Urbanization and water management in Ho Chi Minh City, Vietnamissues, challenges and perspectives. GeoJournal, v.70, p.75-89, 2007. Disponível em: <https://www.researchgate.net/publication/225124562_Urbanization and water management in Ho Chi Minh City Vietnam-issues_challenges_and_perspectives>. Acesso em: 20 de janeiro de 2018.

YOUNG, G.; DEMUTH, S.; MISHRA, A.; CUDENNEC, C. "Hydrological Challenges and Water Security: an Overview", in: Hydrological Sciences and Water Security: Past, Present and Future. Proceedings of the 22th FOUACS Collegium. Paris, June, 2014, IHHS Publ., p. 2-9, 2015. Disponível em: <https://www.proc-iahs.net/366/1/2015/piahs-366-1-2015.pdf>. Acesso em: 20 de janeiro de 2018 